\title{
The effect of metal oxide on the cure, morphology, thermal and mechanical characteristics of chloroprene and butadiene rubber blends
}

\section{Aleksandra Smejda-Krzewicka $^{1} \cdot$ Anna Olejnik $^{1}$ (D) Krzysztof Strzelec ${ }^{1}$}

Received: 20 February 2019 / Revised: 11 September 2019 / Accepted: 17 September 2019 /

Published online: 20 September 2019

(c) The Author(s) 2019

\begin{abstract}
This paper discusses the role of metal oxides $(\mathrm{MeO})$ in the cross-linking process and useful properties of chloroprene and butadiene rubber (CR/BR) blends. Iron(III) oxide $\left(\mathrm{Fe}_{2} \mathrm{O}_{3}\right)$, iron(II,III) oxide $\left(\mathrm{Fe}_{3} \mathrm{O}_{4}\right)$, silver(I) oxide $\left(\mathrm{Ag}_{2} \mathrm{O}\right)$ or zinc oxide were used. It has found that every proposed metal oxide can be used as a cross-linking agent of the CR/BR blends. The degree of cross-linking was evaluated by means of vulcametric parameters, equilibrium swelling in selected solvents and Mooney-Rivlin elasticity constants. The properties of the cured CR/BR products, such as tensile strength, stress at elongation, tension set under constant elongation and compression set, were also investigated. The results revealed that all $\mathrm{CR} / \mathrm{BR} / \mathrm{MeO}$ vulcanizates were characterized by a high cross-linking degree and satisfying mechanical properties. The most important advantage of obtained rubber goods is very high resistance to flame. The increase in the oxygen index value for the $\mathrm{CR} / \mathrm{BR} / \mathrm{Fe}_{2} \mathrm{O}_{3}, \mathrm{CR} / \mathrm{BR} /$ $\mathrm{Fe}_{3} \mathrm{O}_{4}$ and $\mathrm{CR} / \mathrm{BR} / \mathrm{Ag}_{2} \mathrm{O}$ vulcanizates compared to the standard cross-linked chloroprene rubber showed that presented metal oxides provided a positive effect on the resistance to flame of the new $\mathrm{CR} / \mathrm{BR} / \mathrm{MeO}$ composites. Satisfactory properties of the studied blends are related to the presence of the interelastomer bonding of both rubbers in the compositions.
\end{abstract}

Keywords Chloroprene rubber $\cdot$ Butadiene rubber $\cdot$ Metal oxide $\cdot$ Cross-linking $\cdot$ Elastomeric blends · Flammability

Anna Olejnik

anna_olejnik91@o2.pl

1 Institute of Polymer and Dye Technology, Lodz University of Technology, Stefanowskiego 12/16, 90-924 Lodz, Poland 


\section{Introduction}

Chloroprene rubber (CR) is a high-performance material with a wide diversity of applications. It is a homopolymer of chloroprene [1, 2]. Polymer chains have almost entirely trans -1.4 configuration, but the main chain has also a very small amount of cis-1.4, 1.2 and 3.4 structures [3,4]. Unlike other diene elastomers, chloroprene rubber cannot be cross-linked with sulfur due to the presence of substantially inactive $>\mathrm{C}=\mathrm{C}<$ bonds. Therefore, $\mathrm{CR}$ is conventionally cured with 5 phr of zinc oxide $(\mathrm{ZnO})$ in the presence of $4 \mathrm{phr}$ of magnesium oxide $(\mathrm{MgO})$. The mechanism of CR curing is unclear [5]. Chloroprene rubber can be cross-linked with other metal oxides, such as iron(III) oxide, iron(II,III) oxide [6], tin(II) oxide [7], copper(I) oxide or copper(II) oxide [8]. Such obtained CR vulcanizates are often characterized by better mechanical properties than the conventionally crosslinked CR.

Chloroprene rubber is difficult to process; hence, it is often mixed with other elastomers. Blending of different rubbers to combine desirable properties of each component is a very common practice in the rubber industry. Rubber blending allows the production of new materials, obtaining the best processability and cost reduction in rubber product manufacturing process [9]. Chloroprene rubber has recently been combined with other elastomers to achieve special properties of either the CR-based compounds or compounds based on second ingredients. A few reports describe blends of CR with other rubber, such as natural rubber (NR) [10, 11], hydrogenated acrylonitrile-butadiene rubber (HNBR) [12, 13], styrene-butadiene rubber [14], butadiene rubber (BR) [15, 16] or chlorosulfonated polyethylene (CSM) [17] have been published thus far. The Salleh et al. [11] investigated two types of blends containing the natural rubber and chloroprene rubber or epoxidized natural rubber and chloroprene rubber. These blends were cross-linked with sulfur (S) in the presence of tetramethylthiuram monosulfide (TMTM), N-cyclohexyl2-benzothiazylsulfonamide (CBS), zinc oxide $(\mathrm{ZnO})$ and magnesium oxide $(\mathrm{MgO})$. It was found that natural rubber/recycled chloroprene rubber blend cross-linked rapidly than epoxidized natural rubber/ recycled chloroprene rubber blend. In case of the CR/HNBR blends cured with dicumyl peroxide in the presence of zinc oxide, the tensile strength and thermal resistance depend on the amount of CR in these compounds and decrease with the content of CR [13]. Mingyi et al. [15] studied the structure and properties of chloroprene, butadiene rubber and styrene-butadiene-styrene copolymer (CR/BR/SBS) blends. The addition of styrene-butadiene-styrene copolymer to thermodynamically immiscible CR/BR blends improved the homogeneity and increased the tensile strength and cross-link density of vulcanizates. The CR/BR/ SBS blends include sulfur, TMTD, zinc oxide, magnesium oxide and stearic acid. The low-temperature resistance, electrical insulation properties and mechanical properties of CR/BR blends were studied by Zheng et al. [16]. The BR incorporation to $\mathrm{CR}$ improved its low-temperature resistance and electrical insulation properties, while the tensile strength and elongation at break decreased to some extent. These blends were also cross-linked with sulfur in the presence of TMTD, 
$\mathrm{ZnO}$ and $\mathrm{MgO}$. The rheological and mechanical properties and thermal stability of polychloroprene/chlorosulfonated polyethylene (CR/CSM) rubber blends filled with nano- and micro-silica particles were studied by Marković [17]. The density of the nano-silica-filled CR/CSM rubber blends was lower than the micro-silicafilled samples, but the tensile strength and elongation at break were much higher. The nano-silica-filled CR/CSM blends were transparent at all filler concentration and have higher glass transition values than micro-silica-filled compounds. The higher values of the glass transition temperatures for the nano- than the microfilled vulcanizates are indicated by DMA analysis. The nano-filled cross-linked systems have a larger number of SiO-C links than micro-filled cross-linked systems and hence increased stability.

The majority of tested blends containing chloroprene rubber with other elastomers were cross-linked with sulfur in the presence of activator and accelerator. And as we know, the sulfur reacts with unsaturated rubbers occurs through complicated radical substitution in the form of mono-(-S-), di- $\left(-\mathrm{S}_{2}-\right)$ or polysulfide bridges $\left(-S_{x}-\right)$ [18-20]. Unfortunately, the sulfur cross-linking is relatively slow; therefore, it is necessary to use accelerators (e.g., thiazole, sulfonamide) and activators (e.g., $\mathrm{ZnO}, \mathrm{MgO}$ ). These substances reduce the time required for vulcanization, but most of them are harmful to environment and human health. The commonly used accelerators (2-mercaptobenzothiazole, TMTD, CBS) are classified as toxic materials and suspected to be carcinogenic. Additionally, the local vulcanization, reversion, tendency to caking (agglomerates have a negative effect on the vulcanization) and migration on the surface of blends and vulcanizates can occur using sulfur in the process of cross-linking $[18,20]$.

The aim of our research was to analyze the role of selected metal oxide (MeO) on the cross-linking process of CR/BR blends and the properties of the resulting products. The iron(III) oxide [21], the iron(II,III) oxide, the silver(I) oxide or the zinc oxide [22] were proposed. The use of such compounds resulted from the necessity to eliminate the conventional method of cross-linking and its disadvantages. We assumed that the CR/BR blends prepared and cross-linked with selected metal oxide would be characterized by increased resistance to flame and satisfactory thermal and mechanical properties. The blends containing chloroprene and butadiene rubbers have not been cross-linked so far by the method proposed in this work.

\section{Experimental}

\section{Materials}

Chloroprene rubber (CR) (Baypren ${ }^{\circledR} 216 \mathrm{MV}$ from Lanxess GmbH, Dormagen, Germany) and butadiene rubber (BR) (SYNTECA ${ }^{\circledR} 44$ from Synthos S.A., Poland) were used. Commercial additives, such as iron(III) oxide and iron(II,III) oxide, silver(I) oxide and zinc oxide (Sigma-Aldrich Chemical Co. Germany), were used as a crosslinking agent. Stearic acid (Chemical Worldwide Business Sp. z o. o.) was used as a dispersant. 


\section{Preparation and vulcanization of the rubber blends}

The rubber blends were prepared in a conventional way using a laboratory two-roll mill with rolls of following dimensions: diameter $=150 \mathrm{~mm}$ and length $=300 \mathrm{~mm}$. The rotational speed of the front roll was $20 \mathrm{rpm}$ friction $1: 1.25$. The rubber blends were then pressed in an electrically heated hydraulic press. Teflon films were used as spacers preventing the adherence of blend to the press plates. Samples were vulcanizated at a temperature of $160{ }^{\circ} \mathrm{C}$, under pressure of 15 bars for $15 \mathrm{~min}$.

\section{Cure characteristic}

Cross-linking density was determined on the basis of vulcametric measurement, equilibrium swelling, extraction in boiling acetone and Mooney-Rivlin elasticity constants. Vulcametric measurements were taken on a MonTech D-MRD 3000 rheometer for $60 \mathrm{~min}$ at $160{ }^{\circ} \mathrm{C}$ according to ASTM D5289-17 standard. For swelling experiments pieces, weighing 30-50 mg, were cut and immersed in toluene or heptane for $72 \mathrm{~h}$ at room temperature. The swollen samples were weighed on an analytical balance and then dried in a dryer at a temperature of $50{ }^{\circ} \mathrm{C}$ to a constant weight, and after $24 \mathrm{~h}$ they were reweighed. The real extract was calculated on the basis of the equation (Eq. 1):

$$
E_{r}=\frac{m_{1}-m_{2}}{m_{1}}
$$

where $m_{1}$ is the sample weight before extraction $(\mathrm{mg})$ and $m_{2}$ is the sample weight after extraction $(\mathrm{mg})$.

On the basic of the Mooney-Rivlin equation (Eq. 2), the first $\left(2 C_{1}\right)$ and second $\left(2 C_{2}\right)$ elasticity constants were given:

$$
C_{1}+\lambda^{-1} \cdot C_{2}=\frac{P}{2 A_{0} *\left(\lambda-\lambda^{-2}\right)}
$$

where $P$ is the deformation force at $\lambda(\mathrm{kG}), \lambda$ is the deformation $\left(\lambda=l / l_{0}\right), 1$ is the measuring section of the sample loaded with $P(\mathrm{~cm}), l_{0}$ is the measuring section of the unloaded sample $(\mathrm{cm}), A_{0}$ is the cross-sectional area of the unloaded sample $\left(\mathrm{cm}^{2}\right), 2 C_{1}$ is the first elasticity constant $\left(\mathrm{kg} / \mathrm{cm}^{2}\right)$ and $2 C_{2}$ is the second elasticity constant $\left(\mathrm{kg} / \mathrm{cm}^{2}\right)$.

\section{Thermal analysis}

Thermal changes of $\mathrm{CR} / \mathrm{BR} / \mathrm{MeO}$ blends were carried out by differential scanning calorimetry (DSC) using a model DSC1 Mettler Toledo with heating run of -100 to $250{ }^{\circ} \mathrm{C}$ and temperature increase rate $10{ }^{\circ} \mathrm{C} / \mathrm{min}$. 


\section{Morphology studies}

The morphology of the CR/BR was evaluated using a scanning electron microscopy (SEM) by Hitachi S-4700 (Japan) with the ThermoNORAN energy-dispersive spectrometer (EDS) microanalysis adapter. The samples were sputter coated with carbon under high vacuum before an examination. The magnification of image was 5000 .

\section{Thermo-oxidative aging}

The thermal aging of the $\mathrm{CR} / \mathrm{BR} / \mathrm{MeO}$ vulcanizates was performed in a forced circulating aging oven at $70{ }^{\circ} \mathrm{C}$ for 7 days. The aged specimens were then kept for a period of $24 \mathrm{~h}$ at room temperature for attaining the thermal equilibrium before measurements of their mechanical properties (stress at elongation of 100, 200, $300 \%$, tensile strength, elongation at break). The changes of mechanical properties caused by thermo-oxidative aging were evaluated based on aging index $(K)$ (Eq. 3):

$$
K=\frac{\mathrm{TS}_{\mathrm{b}}^{\prime} \cdot E_{\mathrm{b}}^{\prime}}{\mathrm{TS}_{\mathrm{b}} \cdot E_{\mathrm{b}}}
$$

where $\mathrm{TS}_{\mathrm{b}}{ }^{\prime}$ is the tensile strength after thermo-oxidative aging $(\mathrm{MPa}), \mathrm{TS}_{\mathrm{b}}$ is the tensile strength before thermo-oxidative aging $(\mathrm{MPa}), E_{\mathrm{b}}{ }^{\prime}$ is the elongation at break after thermo-oxidative aging $(\%)$ and $E_{\mathrm{b}}$ is the elongation at break before thermooxidative aging $(\%)$.

\section{Mechanical test}

Mechanical properties such as stress at the elongation of $100 \%, 200 \%$ or $300 \%$ $\left(S_{\mathrm{e} 100}, S_{\mathrm{e} 200}, S_{\mathrm{e} 300}\right)$ tensile strength $\left(\mathrm{TS}_{\mathrm{b}}\right)$ and elongation at break $\left(E_{\mathrm{b}}\right)$ of the vulcanizates were tested according to standard PN-ISO 37:2007 by means of a ZWICK tensile tester, model 1435.

\section{Tension set under constant elongation}

Determination of tension set under constant elongation was tested according to standard ISO 2285 by straining device, consisting of a metal rod with pairs of holders, one fixed and one moveable, for the ends of the test piece. Test pieces shall be in shape of stripe between $2 \mathrm{~mm}$ and $10 \mathrm{~mm}$ wide. The length of any given strip depends on the selected reference length and type of straining device. The measurement is taken using the Method C. After measuring the original length, the specimen is slowly elongated to its test length (25\%). After 10-20 min, the elongated distance between markers is determined. Specimens are kept under constant temperature $\left(70{ }^{\circ} \mathrm{C}\right)$ for $22 \mathrm{~h}$. Thereafter, specimens are relaxed slowly and stored for $30 \mathrm{~min}$ on a nonsticking wooden surface. Finally, the relaxation length is determined and tension set $(E)$ is calculated using the equation (Eq. 4): 


$$
E=\frac{\left(L_{2}-L_{1}\right)}{L_{1}} \cdot 100
$$

where $L_{1}$ is the original, unstrained, reference length $(\mathrm{mm})$ and $L_{2}$ is the strained reference length $(\mathrm{mm})$.

\section{Compression set}

Samples for testing (diameter: $30 \mathrm{~mm}$, thickness: $12.5 \mathrm{~mm}$ ) were subjected to compression at $70{ }^{\circ} \mathrm{C}$ for $22 \mathrm{~h}$, in accordance with ISO 815, B method. Spacer plates were used to achieve a deformation of $25 \%$. After $22 \mathrm{~h}$, the samples were cooled in a deformed condition at room temperature for $30 \mathrm{~min}$. After the removal of compressive forces, the samples were conditioned for $30 \mathrm{~min}$, and then, their thickness was measured. On the basis of the results obtained, the compression set (C), expressed as a percentage of the initial compression, is given by the formula (Eq. 5). The testing of each sample was repeated three times.

$$
C=\frac{h_{0}-h_{i}}{h_{0}-h_{\mathrm{s}}} \cdot 100
$$

where $h_{0}$ is the initial thickness of the test piece $(\mathrm{mm}), h_{i}$ is the thickness of the test piece after recovery and $h_{\mathrm{s}}$ is the height of the spacer.

\section{Flammability}

Flammability of the blends was determined by the oxygen index method using a Fire Testing Technology apparatus. The prepared samples with dimensions $50 \times 10 \times 4 \mathrm{~mm}$ were ignited for $5 \mathrm{~s}$ by means of a gas burner supplied with a propane-butane mixture. The constant nitrogen flow rate was $400 \mathrm{l} / \mathrm{h}$, while the concentration of oxygen was chosen so that the sample can be completely burned within $180 \pm 10 \mathrm{~s}$. The oxygen index (OI) was calculated as the percentage of oxygen and nitrogen volume in the mixture (Eq. (6)):

$$
\mathrm{OI}=\frac{\mathrm{O}_{2}}{\mathrm{O}_{2}+\mathrm{N}_{2}}
$$

where $\mathrm{O}_{2}$ is the oxygen flow rate $(1 / h)$ and $\mathrm{N}_{2}$ is the nitrogen flow rate $(1 / h)$.

\section{Results and discussion}

\section{Cross-linking of CR/BR blends with metal oxide}

In this study, the role of metal oxides type on the cross-linking kinetics and the selected properties of blends containing chloroprene and butadiene rubbers (CR/ 
$\mathrm{BR}=75 / 25)$ were assessed. For this purpose, iron(III) oxide $\left(\mathrm{Fe}_{2} \mathrm{O}_{3}\right)$, iron(II,III) oxide $\left(\mathrm{Fe}_{3} \mathrm{O}_{4}\right)$, silver(I) oxide $\left(\mathrm{Ag}_{2} \mathrm{O}\right)$ or zinc oxide $(\mathrm{ZnO})$ [23] were used as crosslinking agents. We have expected that such cured CR/BR blends will be characterized by a high cross-linking degree, but this parameter will depend on the type of used metal oxide.

Table 1 represents the cure characteristics of CR/BR blends cross-linked with different metal oxides. It follows that every proposed metal oxide can be used as a cross-linking agent of $\mathrm{CR} / \mathrm{BR}$ blends. The $\mathrm{MeO}$ type affects the scorch time $\left(t_{02}\right)$. The greatest scorch time $\left(t_{02}=7.77 \mathrm{~min}\right)$ was observed for blend crosslinked with iron(III) oxide, whereas, in the case of $\mathrm{CR} / \mathrm{BR} / \mathrm{Fe}_{3} \mathrm{O}_{4}$ and $\mathrm{CR} / \mathrm{BR} / \mathrm{ZnO}$ blends, shorter scorch time (4.14 min and $3.04 \mathrm{~min}$, respectively) was observed. The incorporation of $\mathrm{Ag}_{2} \mathrm{O}$ into the $\mathrm{CR} / \mathrm{BR}$ blend clearly reduces the scorch time $\left(t_{02}=0.41 \mathrm{~min}\right)$. Based on vulcametric measurements, it was also found that cure time depends on the type of metal oxide. The cure time was almost three times longer when using silver(I) oxide or zinc oxide than when the using iron(III) oxide or iron(II,III) oxide. The viscosity of the blends depends on an elastomers ratio in blends. When the elastomers proportion in the blends is the same, the value of the minimal torque of blends should be similar. The $M_{\min }$ for $\mathrm{CR} / \mathrm{BR} / \mathrm{Fe}_{2} \mathrm{O}_{3}, \mathrm{CR} / \mathrm{B} /$ $\mathrm{Fe}_{3} \mathrm{O}_{4}$ and $\mathrm{CR} / \mathrm{BR} / \mathrm{ZnO}$ blends was in a range of $0.52-0.62 \mathrm{dNm}$, whereas in case of $\mathrm{CR} / \mathrm{BR} / \mathrm{Ag}_{2} \mathrm{O}$ higher value of this parameter $\left(M_{\min }=1.1 \mathrm{dNm}\right)$ was observed. The blend cross-linked with iron(III) oxide exhibits the highest cross-linking degree. For this blend, the torque increment after $30 \mathrm{~min}$ of heating was $6.36 \mathrm{dNm}$, whereas in the case of blends cross-linked with zinc oxide the value of $\Delta M_{30}$ was only 2.95 $\mathrm{dNm}$. This significant difference in torque increment after $30 \mathrm{~min}$ of heating between used metal oxides $\left(\mathrm{Fe}_{2} \mathrm{O}_{3}, \mathrm{Fe}_{3} \mathrm{O}_{4}, \mathrm{Ag}_{2} \mathrm{O}\right.$ or $\mathrm{ZnO}$ ) (step A) can be caused by a different activity of metal oxide in the reaction with hydrogen chloride and thus different rates of the formation of Lewis acid. During the heating of $\mathrm{CR} / \mathrm{BR}$ blend with metal oxide, the Lewis acid $\left(\left[\mathrm{AgCl}_{2}\right]^{-},\left[\mathrm{ZnCl}_{4}\right]^{2-}\right.$ or $\left[\mathrm{FeCl}_{6}\right]^{3-}$ from $\mathrm{Fe}_{2} \mathrm{O}_{3}$ or $\mathrm{Fe}_{3} \mathrm{O}_{4}$ ) (step $\mathrm{B})$ is generated in situ and acts as a catalyst necessary for the interelastomer bonding within the rubbers (step C) [24]. The proposed cross-linking mechanism of CR/BR composites in the presence of metal oxide is shown in Scheme 1.

The effect of the curing agent type on the cross-linking degree was also determined by equilibrium swelling in toluene or heptane (Table 2). The results show that

Table 1 Cure characteristic of CR/BR blends cross-linked with metal oxide (2.5 phr of $\mathrm{Fe}_{2} \mathrm{O}_{3}, \mathrm{Fe}_{3} \mathrm{O}_{4}$, $\mathrm{Ag}_{2} \mathrm{O}$ or $\left.\mathrm{ZnO}\right), T=160{ }^{\circ} \mathrm{C}, t=60 \mathrm{~min}$

\begin{tabular}{llclll}
\hline $\begin{array}{l}\text { Metal oxide } \\
(2.5 \mathrm{phr})\end{array}$ & $t_{02}(\mathrm{~min})$ & $t_{90}(\mathrm{~min})$ & $M_{\min }(\mathrm{dNm})$ & $\Delta M_{15}(\mathrm{dNm})$ & $\Delta M_{30}(\mathrm{dNm})$ \\
\hline $\mathrm{Fe}_{2} \mathrm{O}_{3}$ & 7.77 & 14.50 & 0.62 & 5.81 & 6.36 \\
$\mathrm{Fe}_{3} \mathrm{O}_{4}$ & 4.14 & 9.34 & 0.52 & 4.89 & 4.90 \\
$\mathrm{Ag}_{2} \mathrm{O}$ & 0.41 & 26.51 & 1.10 & 5.03 & 5.47 \\
$\mathrm{ZnO}$ & 3.04 & 33.25 & 0.57 & 2.38 & 2.95 \\
\hline
\end{tabular}

$p h r$ part per hundred parts of rubbers, $t_{02}$ scorch time, $t_{90}$ cure time, $M_{\min }$ minimal vulcametric torque, $\Delta M_{15}, \Delta M_{30}$ torque increment after 15 or 30 min of heating 

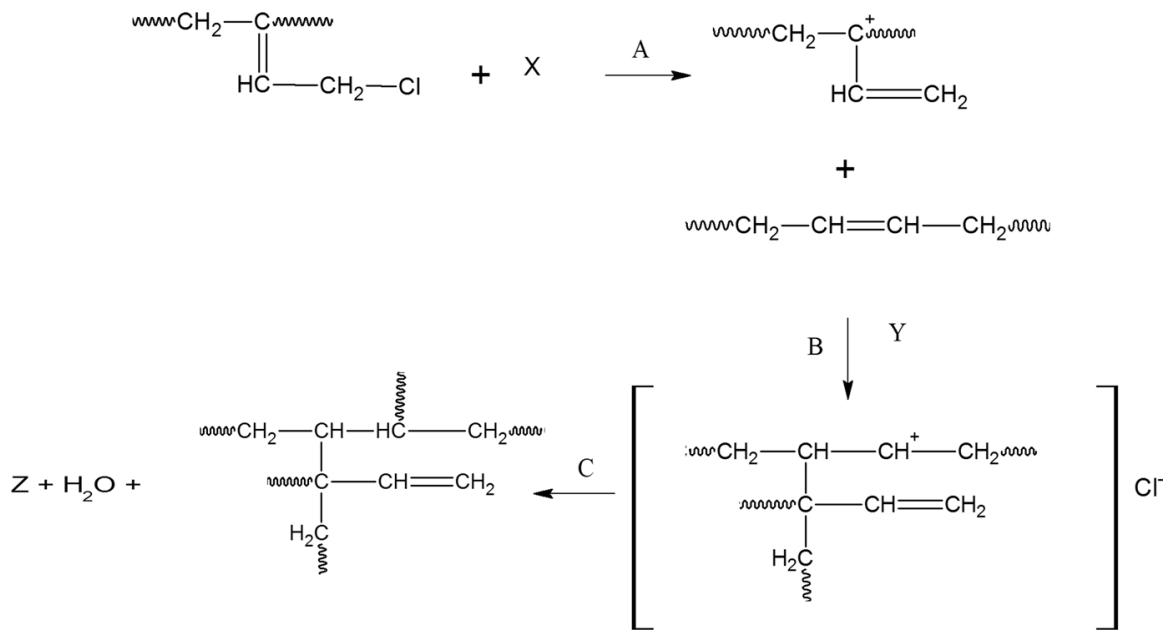

Scheme 1 Cross-linking mechanism of CR/BR blends in the presence of metal oxide (where $X: \mathrm{Fe}_{2} \mathrm{O}_{3}$, $\mathrm{Fe}_{3} \mathrm{O}_{4}, \mathrm{Ag}_{2} \mathrm{O}$ or $\mathrm{ZnO} ; Y:\left[\mathrm{FeCl}_{6}\right]^{3-},\left[\mathrm{AgCl}_{2}\right]^{-},\left[\mathrm{ZnCl}_{4}\right]^{2-} ; \mathrm{Z}: \mathrm{FeCl}_{3}, \mathrm{AgCl}, \mathrm{ZnCl}_{2}$ )

Table 2 Selected properties of $\mathrm{CR} / \mathrm{BR}$ blends cross-linked with metal oxide (2.5 phr of $\mathrm{Fe}_{2} \mathrm{O}_{3}$, $\mathrm{Fe}_{3} \mathrm{O}_{4}, \mathrm{Ag}_{2} \mathrm{O}$ or $\mathrm{ZnO}$ )

\begin{tabular}{lclll}
\hline $\begin{array}{l}\text { Metal } \\
\text { oxide }(2.5 \\
\text { phr) }\end{array}$ & $Q_{\mathrm{v}}^{\mathrm{T}}(\mathrm{ml} / \mathrm{ml})$ & $Q_{\mathrm{v}}^{\mathrm{H}}(\mathrm{ml} / \mathrm{ml})$ & $E_{\mathrm{r}}(\mathrm{mg} / \mathrm{mg})$ & $2 C_{1}\left(\mathrm{kG} / \mathrm{cm}^{2}\right)$ \\
\hline $\mathrm{Fe}_{2} \mathrm{O}_{3}$ & 6.20 & 1.04 & 0.069 & 2.44 \\
$\mathrm{Fe}_{3} \mathrm{O}_{4}$ & 6.80 & 1.13 & 0.057 & 1.85 \\
$\mathrm{Ag}_{2} \mathrm{O}$ & 6.65 & 1.08 & 0.044 & 1.67 \\
$\mathrm{ZnO}$ & 10.90 & 1.30 & 0.050 & 1.26 \\
\hline
\end{tabular}

$Q_{v}^{T}, Q_{v}^{H}$ equilibrium swelling degree in toluene or heptane, $E_{r}$ real extract, $2 C_{1}$ first elasticity constant

the highest cross-linking degree was obtained for the $\mathrm{CR} / \mathrm{BR} / \mathrm{Fe}_{2} \mathrm{O}_{3}$ vulcanizate. The values of $Q_{\mathrm{v}}^{\mathrm{T}}$ for this sample were $6.20 \mathrm{ml} / \mathrm{ml}$. It was also observed that the uptake of the aromatic solvent (toluene) was the highest for the vulcanizate cross-linked with zinc oxide $\left(Q_{\mathrm{v}}^{\mathrm{T}}=10.90 \mathrm{ml} / \mathrm{ml}\right)$. We have studied Mooney-Rivlin elasticity constants to evaluate the cross-linking density. The results confirmed our previous observations. The highest curing degree was achieved for CR/BR blend cross-linked with iron(III) oxide, because in this case the first elasticity constant was $2.44 \mathrm{~kg} / \mathrm{cm}^{2}$. For the blends cured with zinc oxide, the $2 C_{1}$ value was the lowest $\left(1.26 \mathrm{~kg} / \mathrm{cm}^{2}\right)$, which indicates the lowest cross-linking degree. Dependently of the metal oxide used, the different real extract of studied blends was noticed. The sample containing $\mathrm{Fe}_{2} \mathrm{O}_{3}$ was characterized by the largest acetone extract $(0.069 \mathrm{mg} / \mathrm{mg})$, while the smallest $E_{\mathrm{r}}$ value $(0.044 \mathrm{mg} / \mathrm{mg})$ was obtained for the blend cross-linked with $\mathrm{Ag}_{2} \mathrm{O}$. 


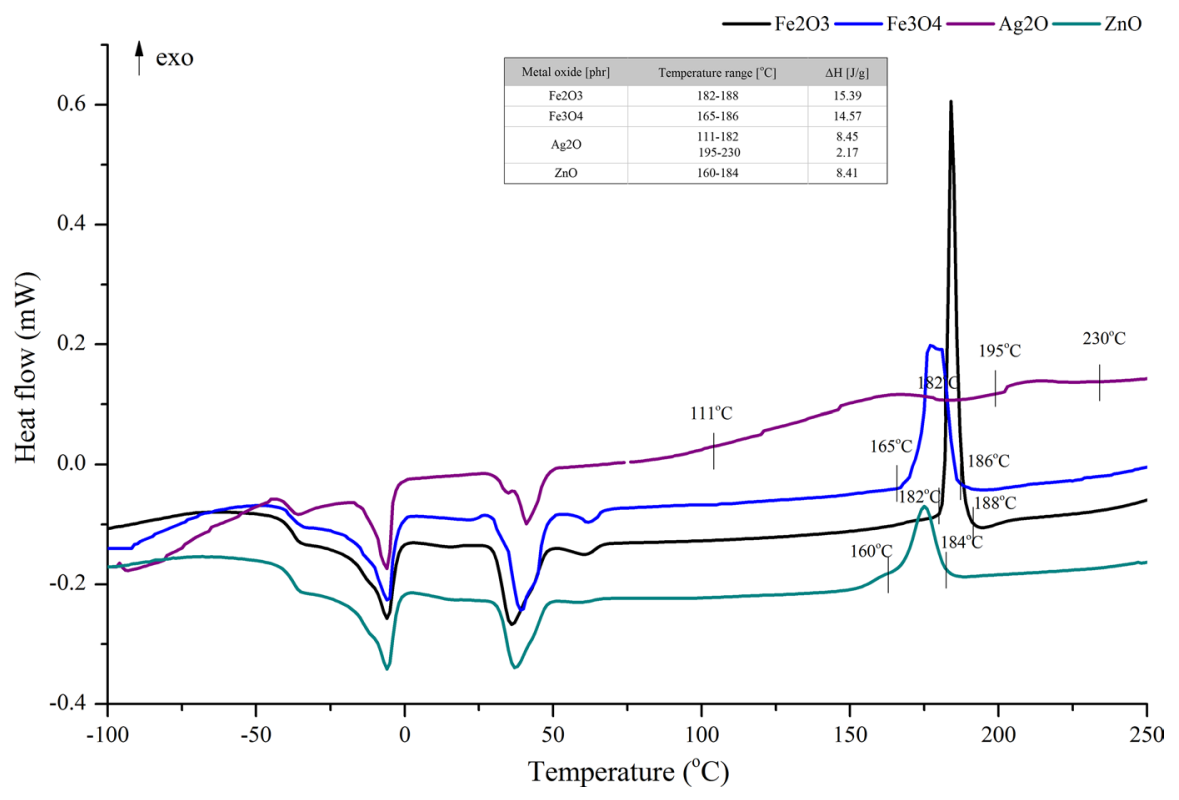

Fig. 1 DSC spectrum of CR/BR blends cross-linked with metal oxide (2.5 phr of $\mathrm{Fe}_{2} \mathrm{O}_{3}, \mathrm{Fe}_{3} \mathrm{O}_{4}, \mathrm{Ag}_{2} \mathrm{O}$ or $\mathrm{ZnO}), \Delta H$-enthalpy

\section{Thermal analysis}

The DCS curves of the CR/BR blends cross-linked with metal oxide are given in Fig. 1. The DSC thermogram is the result of all reactions occurring within the temperature range of interest. During the heating of the rubber compound, many reactions occur competitively; therefore, it is very difficult to measure the enthalpy for a specific reaction. The cross-linking depending on the type of CR/ $\mathrm{BR} / \mathrm{MeO}$ blends takes place in the temperature range from 111 to $230{ }^{\circ} \mathrm{C}$. The enthalpy determined during the cross-linking can be correlated with the crosslinking density. The higher the enthalpy value, the more effective cross-linking process, and thus, the greater degree of cross-linking of the tested vulcanizates. In case of the CR/BR blends cross-linked with iron(III) oxide, the exothermic peak (temperature range from 182 to $188{ }^{\circ} \mathrm{C}$ ) was very intense and narrow, while the enthalpy was the highest $(\Delta H=15.39 \mathrm{~J} / \mathrm{g})$. The cross-linking temperature range for the $\mathrm{CR} / \mathrm{BR} / \mathrm{Fe}_{3} \mathrm{O}_{4}$ blend increased, but the cross-linking enthalpy was also characterized by high value $(\Delta H=14.57 \mathrm{~J} / \mathrm{g})$. The lowest cross-linking enthalpy $(\Delta H=8.41 \mathrm{~J} / \mathrm{g})$ for the $\mathrm{CR} / \mathrm{BR} / \mathrm{ZnO}$ blend was observed. In case of the $\mathrm{CR} / \mathrm{BR} / \mathrm{Ag}_{2} \mathrm{O}$ blend, two exothermic peaks have occurred. The first peak with the cross-linking enthalpy equal to $8.45 \mathrm{~J} / \mathrm{g}$ occurred in the temperature range from 111 to $182{ }^{\circ} \mathrm{C}$, while the second peak with the lower cross-linking enthalpy $\left(\Delta H=2.17 \mathrm{~J} / \mathrm{g}\right.$ ) appeared in the temperature range from 195 to $230{ }^{\circ} \mathrm{C}$. On the basis of determined cross-linking enthalpy, the highest cross-linking degree was 
characterized by the CR/BR blend cured with iron(II) oxide or iron(III,IV) oxide, whereas the lowest degree of cross-linking was characterized by $\mathrm{CR} / \mathrm{BR} / \mathrm{Ag}_{2} \mathrm{O}$. The results obtained from DSC thermogram correlate with the results obtained from equilibrium swelling. As previously mentioned (Table 2), the CR/BR/Fe $\mathrm{O}_{3}$ blend was characterized by the highest degree of cross-linking.

\section{Morphology of CR/BR/MeO vulcanizates}

The morphology of the surface of produced $\mathrm{CR} / \mathrm{BR} / \mathrm{MeO}$ vulcanizates is shown in Fig. 2. Our results show clear differences in the morphology of CR/BR composites cross-linked with various metal oxides. The rough surface with numerous furrows of the CR/BR composites cross-linked with $\mathrm{Fe}_{2} \mathrm{O}_{3}$ or $\mathrm{Fe}_{3} \mathrm{O}_{4}$ was observed. The surface of the $\mathrm{CR} / \mathrm{BR} / \mathrm{Ag}_{2} \mathrm{O}$ vulcanizates consisted of various sizes oval particles that formed larger or smaller aggregates, whereas small and regular distributed particles in an elastomer matrix were presented in the $\mathrm{CR} / \mathrm{BR} / \mathrm{ZnO}$ vulcanizate. On the basis of the EDS analysis, various dispersions of metal oxide in the CR/BR matrix were found. Iron(II,IV) oxide and silver(I) oxide formed smaller or larger aggregates in the elastomer matrix, while iron(III) oxide and zinc oxide have been well dispersed.
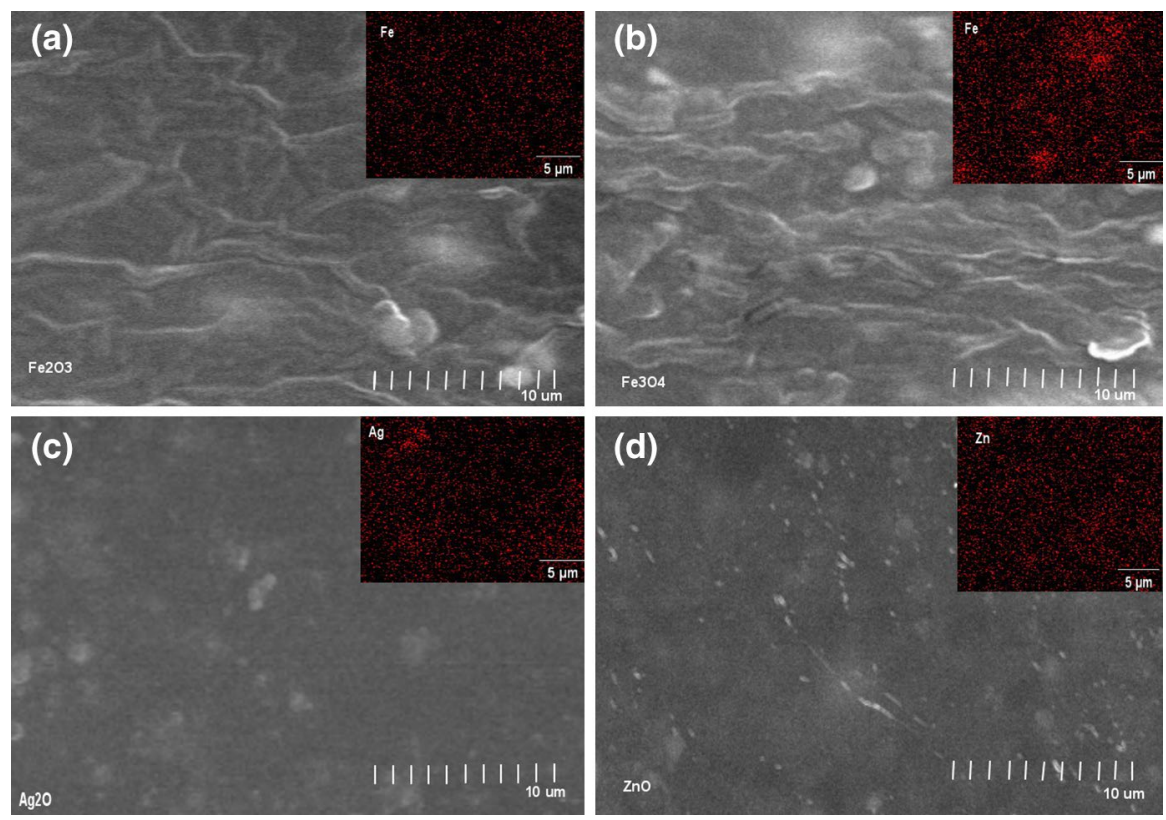

Fig. 2 SEM-EDS photographs of the surface of vulcanizates: a CR/BR/Fe $\mathrm{O}_{3}, \mathbf{b} \mathrm{CR} / \mathrm{BR} / \mathrm{Fe}_{3} \mathrm{O}_{4}, \mathbf{c} \mathrm{CR} /$ $\mathrm{BR} / \mathrm{Ag}_{2} \mathrm{O}$ and $\mathbf{d} \mathrm{CR} / \mathrm{BR} / \mathrm{ZnO}$ 


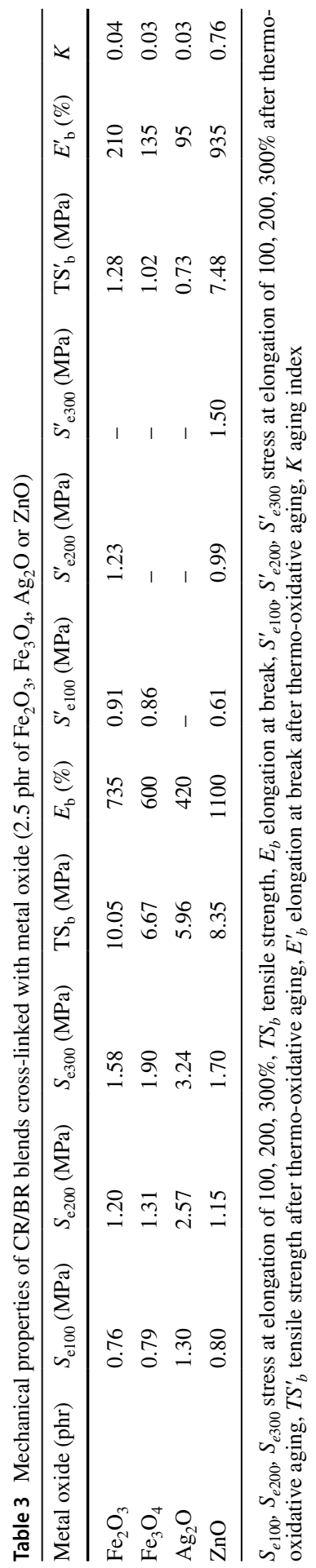




\section{Mechanical properties of $\mathrm{CR} / \mathrm{BR} / \mathrm{MeO}$ vulcanizates}

The mechanical properties (stress at elongation of 100, 200, 300\%, tensile strength and elongation at break) of the $\mathrm{CR} / \mathrm{BR}$ rubber blends were studied (Table 3). In case of $\mathrm{CR} / \mathrm{BR} / \mathrm{Fe}_{2} \mathrm{O}_{3}$ vulcanizates, the highest value of tensile strength $\left(\mathrm{TS}_{\mathrm{b}}=10.05 \mathrm{MPa}\right)$ was obtained, whereas the sample cross-linked with $\mathrm{ZnO}$, which was characterized by the lowest cross-linking degree, achieved tensile strength above $8 \mathrm{MPa}$, while vulcanizates with the addition of iron(II,III) oxide or silver(I) oxide showed the tensile strength equals to $6.67 \mathrm{MPa}$ or $5.96 \mathrm{MPa}$, respectively. It was found that the resulting cured products were characterized by a low resistance to aging factors (Table 3). The mechanical properties for blends cross-linked with $\mathrm{Fe}_{2} \mathrm{O}_{3}, \mathrm{Fe}_{3} \mathrm{O}_{4}$ or $\mathrm{Ag}_{2} \mathrm{O}$ after thermo-oxidative aging were significantly deteriorated. Regardless of the type of cross-linking agent $\left(\mathrm{Fe}_{2} \mathrm{O}_{3}, \mathrm{Fe}_{3} \mathrm{O}_{4}, \mathrm{Ag}_{2} \mathrm{O}\right)$, the $\mathrm{TS}_{\mathrm{b}}^{\prime}$ value was approximately $1.00 \mathrm{MPa}$ and the aging index was $\sim 0.03$. The tensile strength after thermo-oxidative aging for $\mathrm{CR} / \mathrm{BR} / \mathrm{ZnO}$ vulcanizate decreased from $8.35 \mathrm{MPa}$ only to $7.48 \mathrm{MPa}$ (in this case the aging index was 0.76). Such high resistance of this vulcanizate to aging factors is caused by the fact that zinc and its ions have a completely filled subcoat " $d$ " and show an increased stability of the bivalent ions. Due to the fact that the $\mathrm{Fe}$ atoms occur on several degrees of oxidation, the $\mathrm{CR} / \mathrm{BR}$ blends cross-linked with $\mathrm{Fe}_{2} \mathrm{O}_{3}$ or $\mathrm{Fe}_{3} \mathrm{O}_{4}$ reveal worse resistance to aging compared to samples containing $\mathrm{ZnO}$. Silver in compounds also occurs on various degrees of oxidation; therefore, during the aging, the resistance of the CR/BR cured with silver oxide is very poor. Change in the oxidative state of metal in transition groups is one of the factors accelerating the degradation. Deterioration of mechanical properties after aging may be caused by the generation in situ of metal chloride (iron(III) chloride $\left(\mathrm{FeCl}_{3}\right)$ or silver(I) chloride $(\mathrm{AgCl})$ ) upon the heating of $\mathrm{CR} / \mathrm{BR}$ blends in the presence of metal oxide $\left(\mathrm{Fe}_{2} \mathrm{O}_{3}, \mathrm{Fe}_{3} \mathrm{O}_{4}\right.$ or $\left.\mathrm{Ag}_{2} \mathrm{O}\right)$. The metal chloride acts as a catalyst necessary for the interelastomer bonding within the rubbers, as well as this metal chloride also may cause degradation of butadiene rubber or chloroprene rubber, which has been proven by Dragunski [25] and Freitas [26]. Dragunski et al. [25] reported that the degradation of polybutadiene in the presence of iron(III) chloride occurs by the scission of double bonds initiated by cationic species while Freitas et al. [26] showed that polychloroprene in the solution degrades in the presence of $\mathrm{FeCl}_{3} \cdot 6 \mathrm{H}_{2} \mathrm{O}$ combined with an exposure to polychromatic light. This process of such degradation was characterized as a photo-Fenton type.

In addition to the strength properties, the basic method used to determine the mechanical properties of materials is static compression test and static tensile test. Compression set test measures the ability of rubber to return to its original thickness after prolonged compressive stresses at a given temperature and deflection. As a rubber material is compressed over time, it loses its ability to return to its original thickness. Tension set is defined as an extent to which vulcanizates are permanently deformed after stretching for a time. It is expressed as a percentage of the original length, and it is important to many commercial rubber products which expand and contract in normal exploitation. For example, seals and gaskets are usually stretched and they must return to their original size in order to work properly in the specific application. This ability is expressed in the tensile set. Figure 3 shows the tension 


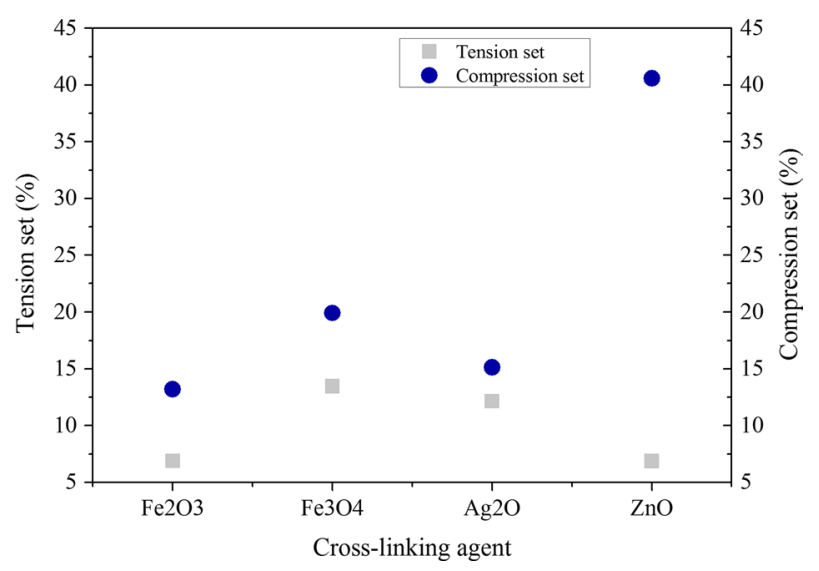

Fig. 3 Tension set and compression set of CR/BR blends cross-linked with metal oxide (2.5 phr of $\mathrm{Fe}_{2} \mathrm{O}_{3}, \mathrm{Fe}_{3} \mathrm{O}_{4}, \mathrm{Ag}_{2} \mathrm{O}$ or $\mathrm{ZnO}$ )

set and compression set of the CR/BR blends cross-linked with various types of cross-linking agent. The studied vulcanizates are characterized by low tension set $(E<15 \%)$, what is desirable for rubber goods. The CR/BR blend cured with $\mathrm{Fe}_{3} \mathrm{O}_{4}$ or $\mathrm{ZnO}$ had the lowest tension set $(E=6.87 \%)$. The highest $E$ value $(14.26 \%)$ was achieved for $\mathrm{CR} / \mathrm{BR} / \mathrm{Fe}_{3} \mathrm{O}_{4}$ sample. The compression set $(C=13-20 \%)$ for the materials cured with $\mathrm{Fe}_{2} \mathrm{O}_{3}, \mathrm{Fe}_{3} \mathrm{O}_{4}$ or $\mathrm{Ag}_{2} \mathrm{O}$ was small, which indicates a high compression resistance. The unsatisfactory result $(C \sim 40 \%)$ has been achieved only for CR/ $\mathrm{BR} / \mathrm{ZnO}$ vulcanizates. Such a large compression set value can be associated with the lowest cross-linking degree of this vulcanizate. The results clearly indicate that all cured blends-except for the $\mathrm{CR} / \mathrm{BR} / \mathrm{ZnO}$ vulcanizate-are characterized by an excellent compression set.

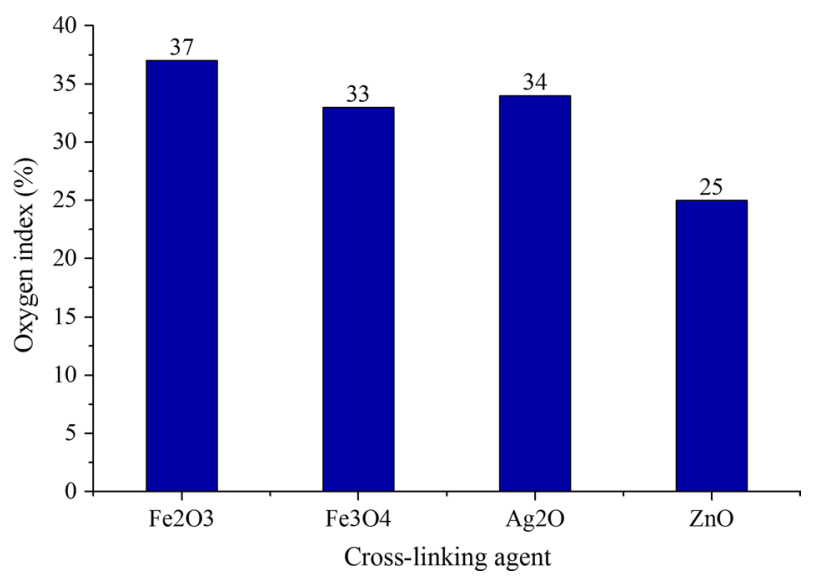

Fig. 4 Oxygen index of CR/BR blends cross-linked with metal oxide (2.5 phr of $\mathrm{Fe}_{2} \mathrm{O}_{3}, \mathrm{Fe}_{3} \mathrm{O}_{4}, \mathrm{Ag}_{2} \mathrm{O}$ or $\mathrm{ZnO})$ 


\section{Flammability}

The oxygen index $(\mathrm{OI})$ value of $\mathrm{CR} / \mathrm{BR} /$ metal oxide vulcanizates are presented in Fig. 4. When the OI values of these composites were compared, it was found that the order in which the metal oxides increased the OI values was as follows: $\mathrm{ZnO}<\mathrm{Ag}_{2} \mathrm{O}<\mathrm{Fe}_{3} \mathrm{O}_{4}<\mathrm{Fe}_{2} \mathrm{O}_{3}$. The increase in the OI value for $\mathrm{CR} / \mathrm{BR} / \mathrm{Fe}_{2} \mathrm{O}_{3}, \mathrm{CR} /$ $\mathrm{BR} / \mathrm{Fe}_{3} \mathrm{O}_{4}$ and $\mathrm{CR} / \mathrm{BR} / \mathrm{Ag}_{2} \mathrm{O}$ compared to the standard cross-linked $\mathrm{CR}(\mathrm{OI}=26 \%)$ [27] showed that these metal oxides provide a positive influence on the flammability of the $\mathrm{CR} / \mathrm{BR}$ composites. However, the oxygen index of $\mathrm{CR} / \mathrm{BR} / \mathrm{ZnO}$ composites showed a slight decrease $(\mathrm{OI}=25 \%)$. These produced vulcanizates belong to a flame retardant material [28]. The use of $\mathrm{Fe}_{2} \mathrm{O}_{3}, \mathrm{Fe}_{3} \mathrm{O}_{4}$ or $\mathrm{Ag}_{2} \mathrm{O}$ as a cross-linking agent of $\mathrm{CR} / \mathrm{BR}$ blends leads to the production of nonflammable materials $(\mathrm{OI}>28.0 \%)$ [28]. Such differences in the obtained values of the oxygen index are probably due to the different ability of metals (in the used metal oxides) to form chloride complex compounds. The metals of groups 3-10 of the periodic table of elements, which are not fully filled subcoats d, are characterized by a particularly large tendency to form chloride complex compounds [29]. The higher ability to form complexes, the higher thermal stability, and thus, the increased resistance to fire [30]. The highest OI value obtained for $\mathrm{CR} / \mathrm{BR} / \mathrm{Fe}_{2} \mathrm{O}_{3}$ vulcanizate is probably due to Fe's ability to form an octahedral complex. In the case of silver atoms, the ability to form complex compounds is much smaller than for iron atoms, while the zinc does not form coordination compounds. Compounds during the combustion of the $\mathrm{CR} / \mathrm{BR} / \mathrm{metal}$ oxide may form between the metal ion and the chlorine-evolving atoms detaching themselves from the main chain of the chloroprene rubber. The resulting compounds inhibit the radical reaction of the combustion of the polymeric material.

\section{Conclusion}

The presented metal oxide-iron(III) oxide, iron(II,III) oxide, silver(I) oxide, zinc oxide - can be used as the cross-linking agents of new chloroprene and butadiene rubber $(\mathrm{CR} / \mathrm{BR})$ blends. The type of metal oxide affects on the curing degree and thermal and mechanical properties of the resulting rubber materials. Based on performed tests, it has found that cured CR/BR blends, regardless of the type of metal oxide, were characterized by a high cross-linking degree and good mechanical and thermal properties. The satisfactory mechanical properties of $\mathrm{CR} / \mathrm{BR} / \mathrm{MeO}$ vulcanizates probably result from the formation of interelastomer bonds between chloroprene and butadiene rubbers. The DSC curves show the significant changes in the intensities and widths of the exothermic peak in the temperature range from 111 to 230 caused by the difference rate of in situ formation of Lewis acid. Additionally, the advantages of proposed $\mathrm{CR} / \mathrm{BR} / \mathrm{Fe}_{2} \mathrm{O}_{3}, \mathrm{CR} / \mathrm{BR} / \mathrm{Fe}_{3} \mathrm{O}_{4}, \mathrm{CR} / \mathrm{BR} / \mathrm{Ag}_{2} \mathrm{O}$ and $\mathrm{CR} / \mathrm{BR} / \mathrm{ZnO}$ products are simple technology and low cost of the production of flame retardant or nonflammable materials. 
Authors contribution All authors contributed to the study conception and design. Material preparation, data collection and analysis were performed by Smejda-Krzewicka Aleksandra, Olejnik Anna and Strzelec Krzysztof. The first draft of the manuscript was written by Aleksandra Smejda-Krzewicka, and all authors commented on previous versions of the manuscript. All authors read and approved the final manuscript.

\section{Compliance with ethical standards}

Conflict of interest The authors declare that they have no conflict of interest.

Human participants or animals rights This article does not contain any studies with human participants or animals performed by any of the authors.

Open Access This article is distributed under the terms of the Creative Commons Attribution 4.0 International License (http://creativecommons.org/licenses/by/4.0/), which permits unrestricted use, distribution, and reproduction in any medium, provided you give appropriate credit to the original author(s) and the source, provide a link to the Creative Commons license, and indicate if changes were made.

\section{References}

1. Klingender RC (2008) Handbook of specialty elastomers. CRC Press, Boca Raton

2. Ahmed K, Nizami SS, Raza NZ, Shirin K (2012) Cure characteristics, mechanical and swelling properties of marble sludge filled EPDM modified chloroprene rubber blends. Adv Mat Phys Chem 2:90-97. https://doi.org/10.4236/ampc.2012.22016

3. Akiba M, Hashim AS (1997) Vulcanization and crosslinking in elastomers. Prog Polym Sci 22:457-521

4. Smejda-Krzewicka A, Rzymski WM, Kowalski D (2015) Tin oxide cross-linking of chloroprene rubber. Polimery 60:186-191. https://doi.org/10.14314/polimery.2015.186

5. Li J, Isayev AI, Ren X, Soucek MD (2016) Effect of norbornyl modified soybean oil on CR-filled chloroprene rubber. J App Polym Sci 133:43809. https://doi.org/10.1002/APP.43809

6. Rzymski WM, Bociong K, Pizon P, Kajkowski R (2014) Crosslinking method for chloroprene rubber, PL Patent 216835

7. Janowska G, Rzymski WM, Smejda-Krzewicka A, Bociong K, Kowalski D (2013) The method of cross-linking and modification of chloroprene rubbers, PL Patent 215569

8. Smejda-Krzewicka A, Dmowska-Jasek P, Kobędza P (2016) Crosslinking method for chloroprene rubber. Polish Patent Declaration P.415996

9. Ismail H, Suzaimah S (2000) Styrene butadiene rubber/epoxidized natural rubber blends: dynamic properties, curing characteristics and swelling studies. Polym Test 19:879-888. https://doi. org/10.1016/S0142-9418(99)00058-6

10. Ismail H, Leong HC (2001) Curing characteristics and mechanical properties of natural rubber/chloroprene rubber and epoxidized natural rubber/chloroprene rubber blends. Polym Test 20:509-516. https://doi.org/10.1016/S0142-9418(00)00067-2

11. Salleh SZ, Ahmed MZ, Ismail H (2016) Properties of natural rubber/recycled chloroprene rubber blend: effects of blend ratio and matrix. Proc Chem 19:346-350. https://doi.org/10.1016/j.proch e.2016.03.022

12. Severe G, White JL (2004) Dynamically vulcanized blends of oil-resistant elastomers with HNBR. J App Polym Sci 95:2-5. https://doi.org/10.1002/app.20813

13. Wang TT, Zhong GL, Zhou LL (2013) Research on mechanical properties, compatibility, flame retardancy, hot-air ageing resistance of hydrogenated nitrile-butadiene rubber/chloroprene rubber blends. Adv Mater Res 750-752:816-819. https://doi.org/10.4028/www.scientific.net/ AMR.750-752.816

14. Das A, Basu DK (2005) Evaluation of physical and dielectric properties of chloroprene and styrene butadiene rubber blends. J App Polym Sci 96:1492-1504. https://doi.org/10.1002/app.21280 
15. Mingyi L, Hua Z, Jianfeng L (1999) Study on the compatibility of BR/CR/SBS blends by using small amounts of SBS. J App Polym Sci 71:215-220. https://doi.org/10.1002/(SICI)10974628(19990110)71:2\%3c215:AID-APP4\%3e3.0.CO;2-O

16. Zheng J, Tan J, Gao H, Wang C, Dong Z (2014) Preparation of low temperature resistant and high electrical insulation chloroprene rubber-butadiene rubber blends. Rubber Chem Technol 2:360369. https://doi.org/10.5254/rct.13.86963

17. Marković G, Samarzija-Javanović S, Jovanović V, Marinović-Cincović M (2010) Thermal stability of CR/CSM rubber blends filled with nano- and micro-silica particles. J Therm Anal Calorym 100:881-888. https://doi.org/10.1007/s10973-009-0562-X

18. Sung-Hyo C, Dong-Ho C (1996) Kinetics of sulfur vulcanization of NR, BR, SBR, and their blends using a rheometer and DSC. J App Polym Sci 61:449-454. https://doi.org/10.1002/(SICI)10974628(19960718)61:3\%3c449:AID-APP7\%3e3.0.CO;2-I

19. Xiang HP, Qian HJ, Lu ZY, Rong MZ, Zhang MQ (2015) Crack healing and reclaiming of vulcanized rubber by triggering the rearrangement of inherent sulfur crosslinked networks. Green Chem 17:4315-4325. https://doi.org/10.1039/c5gc00754b

20. Coran AY (2003) Chemistry of the vulcanization and protection of elastomers: a review of the achievements. J App Polym Sci 87:24-30. https://doi.org/10.1002/app.11659

21. Smejda-Krzewicka A, Olejnik A, Dmowska-Jasek P, Strzelec K (2016) The method of cross-linking and modification of chloroprene rubber and butadiene rubber blends. Polish Patent Declaration P.416236

22. Smejda-Krzewicka A, Olejnik A, Strzelec K (2016) The method of cross-linking and modification of chloroprene rubber and butadiene rubber blends. Polish Patent Declaration P.418098

23. Olejnik A, Smejda-Krzewicka A, Strzelec K (2019) New elastomeric blends with increased resistance to flame. Polimery 1:43-47. https://doi.org/10.14314/polimery.2019.1.5

24. Olejnik A, Smejda-Krzewicka A, Strzelec K, Szynkowska MI (2019) Curing and properties of chloroprene and butadiene rubber (CR/BR) blends cross-linked with copper(I) oxide or copper(II) oxide. Intern J Polym Anal Charact 24:18-31. https://doi.org/10.1080/1023666X.2018.1514696

25. Dragunski DS, Freitas AR, Rubirar AF, Muniz EC (2000) Influence of iron(III) chloride on the degradation of the polyisoprene and polybutadiene. Polym Degrad Stab 67:239-247. https://doi. org/10.1016/s0141-3910(99)00119-6

26. Freitas AR, Vidotti GJ, Rubira AF, Muniz EC (2005) Polychloroprene degradation by a photo-fenton process. Polym Degrad Stab 87:425-432. https://doi.org/10.1016/j.polymdegradstab.2004.10.003

27. Hilado CJ (1998) Flammability handbook for plastics. Technomic Publishing Company, New York

28. Jurkowski B, Jurkowska B, Rydarowski H (2009) Some aspects of flammability of polymer composition. Publishing House of Cracow University of Technology, Cracow

29. Cieślak-Golonka M, Starosta J, Wasielewski M (2018) Introduction to coordination chemistry. PWN, Warsaw

30. Wu N, Yang R (2011) Effects of metal oxides on intumescent flame-retardant polypropylene. Polym Adv Technol 22:495-501. https://doi.org/10.1002/pat.1539

Publisher's Note Springer Nature remains neutral with regard to jurisdictional claims in published maps and institutional affiliations. 